International Journal of Engineering \& Technology, 9 $(1)(2020) 252-257$
International Journal of Engineering \& Technology
SPC
Website: www.sciencepubco.com/index.php/IJET
Research paper

\title{
Fatigue strength of a tensile-shear loaded clinched joint made from an al-5052 alloy sheet
}

\author{
J. J Han ${ }^{1}$, W. T. Hwang ${ }^{1}$, C. E. Lee ${ }^{1}$, H. K Kim ${ }^{2 *}$ \\ ${ }^{1}$ Graduate School, Dept. of Automotive Engineering, Seoul National University of Science and Technology \\ ${ }^{2}$ Dept. of Mechanical and Automotive Engineering, Seoul National University of Science and Technology, Seoul, \\ 01811, Republic of Korea \\ *Corresponding author E-mail: kimhk@seoultech.ac.kr
}

\begin{abstract}
The clinching process has been shown to be able to join dissimilar material sheets as an alternative to spot welding. In this study, monotonic and fatigue tests were conducted using tensile-shear specimens for an evaluation of the strengths of a joint. In the fatigue tests, an interface failure occurred. The fatigue ratio of the joint is 0.29 , assuming a fatigue endurance limit at 2 x106 cycles. The maximum vonMises stress of the joint at the load amplitude corresponding to the fatigue endurance limit is slightly higher than the yield strength of Al5052 alloy. This indicates that the strength of the neck region is increased partially due to work hardening.
\end{abstract}

Keywords: Clinched Joint; Tensile-Shear Specimen; Interface Failure Mode; Fatigue Strength; Fatigue Ratio.

\section{Introduction}

Recently, the clinching process is considered to be capable of joining sheets of dissimilar material as an alternative to spot welding [1-3]. Clinching is a joining method in which metal sheets are cold-deformed locally with a punch and die by forming an interlock between the sheets. The process is a combination of drawing and pressing to lock together metal sheets to be joined without the use of any additional element or a thermal effects.

Over the last 30 years, clinching has been applied in industry, and several studies focusing on the strengths of joints created by clinching have been conducted [4-10]. For example, Kaščák et al. investigated the load-bearing capacity of clinched joints consisting of a combination of steel and aluminum alloy sheets under tensile-shear loading [4]. They reported that the combination with the aluminum alloy sheet on the die side had a higher load-bearing capacity of the clinched joint when compared to that when the steel sheet was on the die side. Kovács and Tisza investigated the monotonic strengths of clinched joints using tensile-shear, coach-peel and U-shaped specimen geometries with a combination of aluminum alloy and steel sheets [5]. The aluminum sheets underwent two heat treatments: a solution heat treatment and T6 aging. They reported that such a heat treatment can improve the flow of the material and consequently enhance the mechanical behavior of the joints. Lin et al. compared the fatigue behavior of self-piercing rivets and clinch joints of aluminum sheets [6] They reported that fatigue cracks start from the curved interfacial surface of the upper sheet and then grow into the upper sheet thickness for both types under cyclic loading conditions. They proved that the fatigue lifetimes can be properly estimated by adopting a structural stress model. Zhao et al. studied ductile fracture behavior of clinched joint using a modified Rousselier model [7]. They reported that the modified model could predict the failure mechanisms and fracture locations of clinched joint. The damage coefficients obtained from calibrated specimens were reported to describe the clinching process and the failure evolution process. Carboni et al. investigated the fatigue behavior of clinched joints of steel sheets under tensile-shear loading [8]. They reported that the stress ratio influenced the failure mode and that the fatigue limit was $50 \%$ of the ultimate strength. This result indicated a significantly higher value than that of spot welding. Kim and Kim investigated monotonic and fatigue strengths of clinched joints using coach-peel and cross-tension type specimens in a cold-rolled mild steel sheet [9]. They reported that the coach-peel and cross-tension specimen geometries exhibit very low fatigue ratio, compared to that of a tensile-shear specimen. Additionally, the Smith-Watson-Topper fatigue parameter was reported to be an appropriate predictor of the fatigue lifetimes of these joints.

However, very few other studies have concentrated on fatigue strength capabilities of the joints $[6,8,9]$. Therefore, in this study, the monotonic and fatigue strengths of clinched joints in tensile-shear specimens consisting of aluminum Al-5052 sheets are evaluated. A commercial finite element method (FEM) program is used to conduct a structural analysis of the specimen geometries.

\section{Experimental procedures}

The mechanical properties and the chemical composition of the aluminum Al-5052 alloy sheet ( $0.8 \mathrm{~mm}$ thick) are shown in Table 1 and Table 2, respectively. In this study, the round clinch joining method developed by TOX Co. was utilized. An electro-hydraulic universal 
testing machine (Instron 8516) with a capacity of $100 \mathrm{kN}$ was used as the clinch joining device. The upper and lower sheets consisted of Al-5052 alloy. Table 3 shows the dimensions of the cross-section of the joint corresponding to a button on the prepared specimen. Tensile-shear specimens with a 30-mm-long overlap were used in both static and fatigue tests. These specimens were $30 \mathrm{~mm}$ wide and had a single clinched button at the center of the overlap. The monotonic and fatigue strength of clinched joint were measured using the Instron 8516. The monotonic test was carried out at a speed of $2 \mathrm{~mm} / \mathrm{min}$. The fatigue tests were carried out using a cyclic load with a $10 \mathrm{~Hz}$ sine wave form at a stress ratio $\mathrm{R}\left(=\mathrm{P}_{\min } / \mathrm{P}_{\max }\right)$ of 0.1 .

A FEA (finite element analysis) was conducted using the commercial software ABAQUS (version 6.6) as the solver and HyperMesh (version 14.0) as the pre- and post-processor. The tensile-shear specimen was fully modeled using linear hexahedron (eight-node) and linear prism (six-node) elements. Contact elements between the substrate faces with a friction coefficient of 0.2 were introduced by means of a master-slave technique. A linear-elastic material model was used in the FEA.

Table 1: Mechanical Properties of the Base Metal

\begin{tabular}{lllll}
\hline Material & $\sigma_{\mathrm{u}}(\mathrm{MPa})$ & $\sigma_{\mathrm{y}}(\mathrm{MPa})$ & $\mathrm{E}(\mathrm{GPa})$ & Elongation $(\%)$ \\
\hline Al-5052 & 273.6 & 213.8 & 78.3 & 12 \\
\hline
\end{tabular}

Table 2: Chemical Compositions of the Base Metal (Wt. \%)

\begin{tabular}{lllllllll}
\hline Material & $\mathrm{Mg}$ & $\mathrm{Mn}$ & $\mathrm{Fe}$ & $\mathrm{Cr}$ & $\mathrm{Si}$ & $\mathrm{Cu}$ & zn & $\mathrm{Al}$ \\
\hline Al-5052 & 2.8 & 0.10 & 0.40 & 0.35 & 0.25 & 0.10 & 0.1 & bal. \\
\hline
\end{tabular}

Table 3: Dimensions of Cross-Section of the Clinched Joint with A Punching Force of $32 \mathrm{KN}$

\begin{tabular}{lll}
\hline Items & Definition & Size $(\mathrm{mm})$ \\
\hline $\mathrm{BD}$ & Button diameter & 8.3 \\
$\mathrm{CT}$ & Cap thickness & 0.5 \\
$\mathrm{e}$ & Eccentricity & 1.8 \\
$\mathrm{~h}$ & Height & 2.2 \\
$\mathrm{NT}$ & Neck thickness & 0.4 \\
$\mathrm{PD}$ & Punch diameter & 5.4 \\
$\mathrm{t}_{1}$ & Punch side sheet thickness & 0.8 \\
$\mathrm{t}_{2}$ & Die side sheet thickness & 0.8 \\
\hline
\end{tabular}

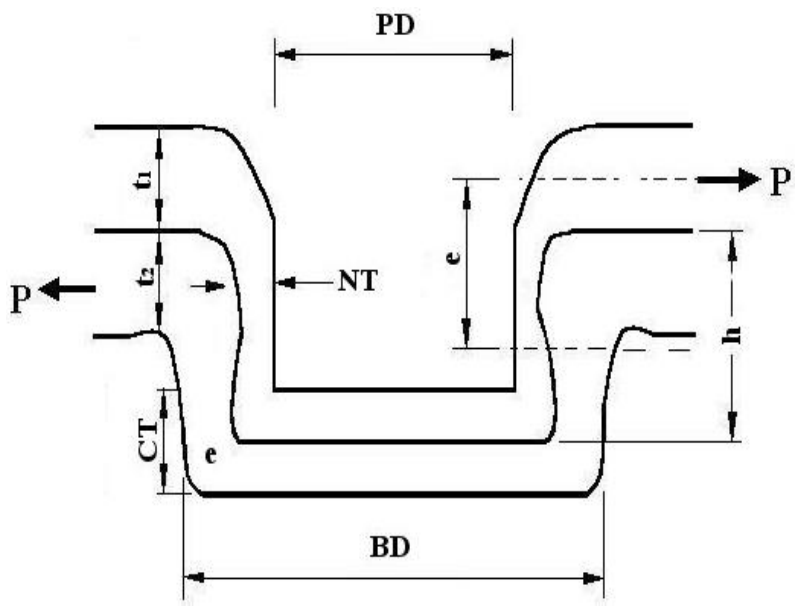

Fig. 1:

\section{Experimental results and discussions}

\subsection{Optimal punching force and monotonic strengths of the joints}

The strength of the clinched joint specimen is related to certain dimensions, such as the sheet thickness, punch diameter, and the punching force. In this study, monotonic tests were carried out using tensile-shear specimens with varying punching forces to determine the optimum punching force.

Fig. 1 shows the vertical displacement of the upper and lower sheets with respect to the punching force when the Al-5052 sheets are joined. This figure is very similar to a load-versus-vertical displacement plot [11] of the typical clinch joining process. In this figure, the process during which vertical displacement up to approximately $1.6 \mathrm{~mm}$ is applied consists of the initial shear insertion, upsetting and spreading steps. The punch force causes a local indentation. The punch presses a certain part of the sheet metal to reduce the sheet thickness by means of axial compression. The sheet metal above the die is pressed against the floor surface of the die. At this time, during the insertion process, there is a plastic zone formed by the gap between the punch and the die, and a certain amount of sheet metal is in contact with the die side. As the pressing continues, the metal sheet approaches the ring groove of the cylindrical die. The second step, which corresponds to a vertical displacement of about $2.5 \mathrm{~mm}$, is the step of filling the upper die section, in which the area of the die surrounding the punch fills up continuously. This leads to a vertically linear increase in the punching force. On the other hand, the punching force increases sharply when the displacement exceeds $2.5 \mathrm{~mm}$, and, the sheet metal fills the ring groove completely. At this time, the flow resistance of the metal increases continuously in the ring groove and the greatest load is exerted on the circumference of the die. The rapid increase in punching force at this time is a process similar to the force behavior in the close-die cold forging process. 


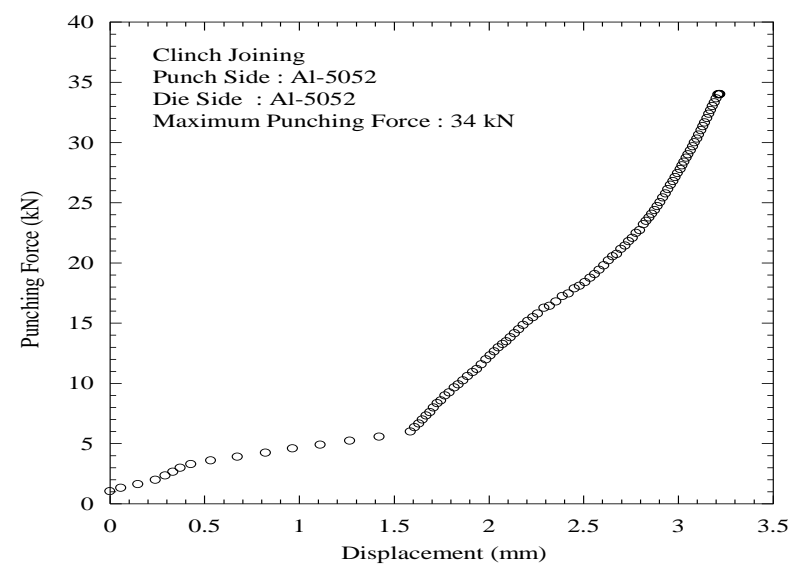

Fig. 1: Punching Force against the Displacement of Clinched Joints of Al-5052 Sheets.

The maximum vertical displacement with respect to the punching force is shown in Fig. 2. The maximum displacement is proportional to the punching force in the range of $28 \mathrm{kN}$ to $33 \mathrm{kN}$, but the displacement slows past this force range. An observation of the degree of joining relative to the punching force shows that the degree of joining is appropriate after $30 \mathrm{kN}$. Especially, when the punching force is 34 $\mathrm{kN}$, there is almost no clearance between the upper and lower sheets.



Fig. 2: Punching Force against the Maximum Displacement during the Clinch Joining Process.

Three tensile-shear specimens were produced for each punching force and monotonic strength tests were performed to determine the optimum punching force in terms of the monotonic strength of the tensile-shear specimen. Fig. 3 shows the applied load and displacement curves of the three tensile-shear specimens produced by applying punch force of $29 \mathrm{kN}$. In all of the test specimens, the maximum load peaked at approximately $1040 \mathrm{~N}$. Cracking occurs at the maximum applied load, after which the upper sheet becomes partially separated from the lower sheet and pulled up at the joint. The applied load did not decrease directly after the occurrence of cracking at the peak load, but the applied load was maintained for a certain period time with a small decrement of the load. This tendency usually depends on the material of the upper sheet, which is apparent when the upper sheet is thick and ductile. Thin and brittle materials do not exhibit this behavior [12]. With regard to cause of this behavior, for a specimen with a thick and ductile sheet material as an upper sheet, the neck thickness (NT), which is the weakest part of the joint, is thick enough to maintain an applied load. As the buttons become partially separated from each other, this behavior occurs, during which the opposite side of the button is lifted up. On the other hand, for a joint of thin and brittle sheet material, the neck thickness (NT) is relatively thin, which causes an abrupt shear fracture under the peak load [12].

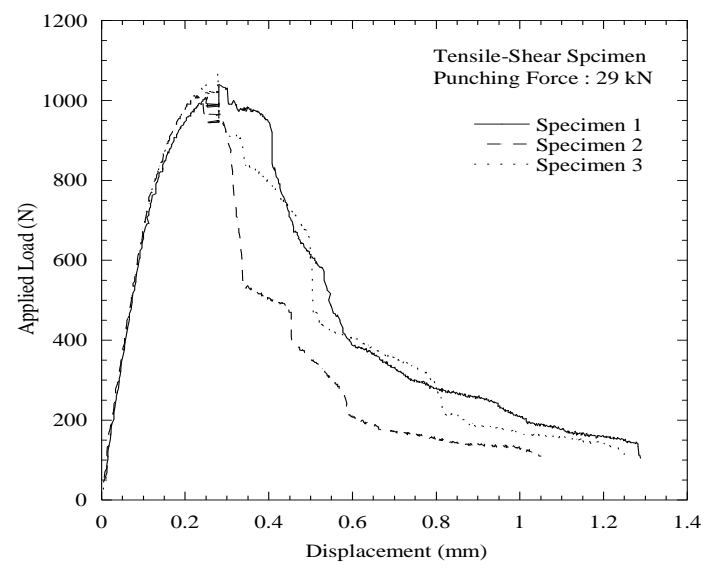

Fig. 3: Displacement against Tensile Applied Load Curves for the Tensile-Shear Specimens. 
The maximum loads of the specimen produced by each punching force are shown in Fig. 4. In the monotonic tests of the tensile-shear specimens, two types of failure modes were observed: the interface failure mode and the pull-out failure mode. The interface failure mode is when cracking occurs in the neck thickness (NT) and cracks propagate along the surfaces. The pull-out failure mode is a failure in which the upper and lower sheets of the button are separated while cracks are initiated in the upper sheet of the button (BD) and then propagate along the weak neck thickness (NT). As shown in Fig. 4, when the punching force is $26 \mathrm{kN}$ or less, the pull-out failure mode appears. This occurs because the upper and lower sheets are separated due to the insufficient punching force. However, at more than 27 $\mathrm{kN}$, fracture occur due to interface failure. The maximum load is increased with an increment in the punching force. However, at more than $27 \mathrm{kN}$, the fracture mode is the interface failure mode. The punching force increases as the maximum load increases and then decreases again after $32 \mathrm{kN}$. Therefore, the optimum punching force for the specified sheet thickness $(=0.8 \mathrm{~mm})$ and punch diameter $(=5.4$ $\mathrm{mm}$ ) was determined to be $32 \mathrm{kN}$. All of the tensile-shear specimens used in the fatigue tests were produced by applying punching force of $32 \mathrm{kN}$.

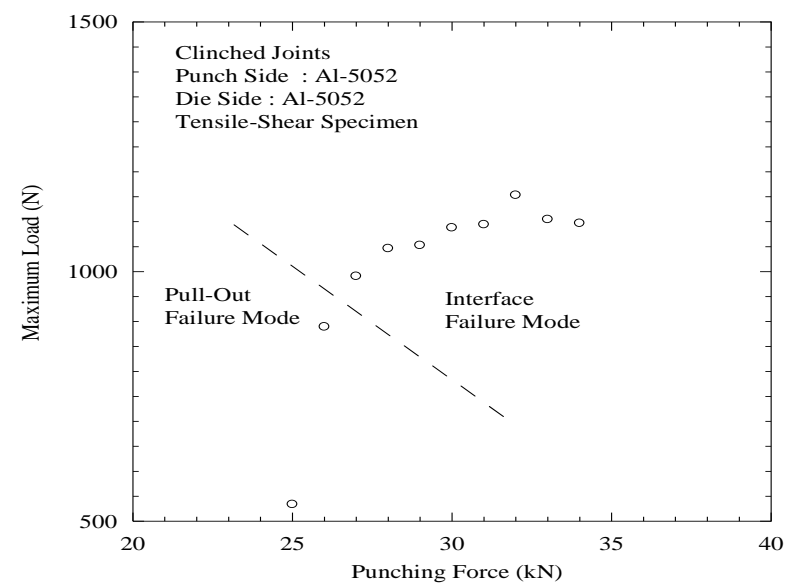

Fig. 4: Punching Force against the Maximum Tensile-Shear Load for the Clinched Joint Specimens.

\subsection{Fatigue lifetime evaluation}

All the fatigue-tested specimens fractured in the interface failure mode, during which cracks initiated closest to the neck thickness (NT) and propagated on the neck surface, and finally fractured. Fig. 5 shows the relationship between the load amplitudes and the fatigue lifetimes of the specimens. The fatigue endurance limit load was $331 \mathrm{~N}$, based on $2 \times 106$ cycles. The fatigue ratio (=fatigue endurance limit /ultimate tensile strength) is approximately $29 \%$ of the maximum load (= $1154 \mathrm{~N})$. According to the research by Saathoff and Mallick [13], the ratio of the maximum fatigue load to the static failure load of clinched joints in Al-6111-T4 aluminum alloy sheets at two million cycles under tensile-shear loading is approximately 0.65 . If this ratio is converted into the fatigue ratio, the value of the fatigue ratio will be 0.29 considering a load ratio $\mathrm{R}$ of 0.1 . This ratio of 0.29 is very close to the value $(=0.29)$ found in the present study. The fatigue ratio for the tensile-shear geometry of a mild steel sheet was reported to be 0.43 [14]. This indicates that the fatigue ratio of clinched joints in aluminum alloy is lower than that of clinched joints in mild steel sheets. This behavior is partially due to the lower fatigue ratio of the aluminum alloy compared to that of steel. The fatigue ratio of steel is known to be approximately 0.5 , while that of wrought aluminum alloys is approximately 0.4 , up to the fatigue endurance limit of $130 \mathrm{MPa}$ [15]. The fatigue ratios for the cross-tension and coachpeel specimen geometries of mild steel sheets were reported to be 0.06 and 0.08 , respectively [9].

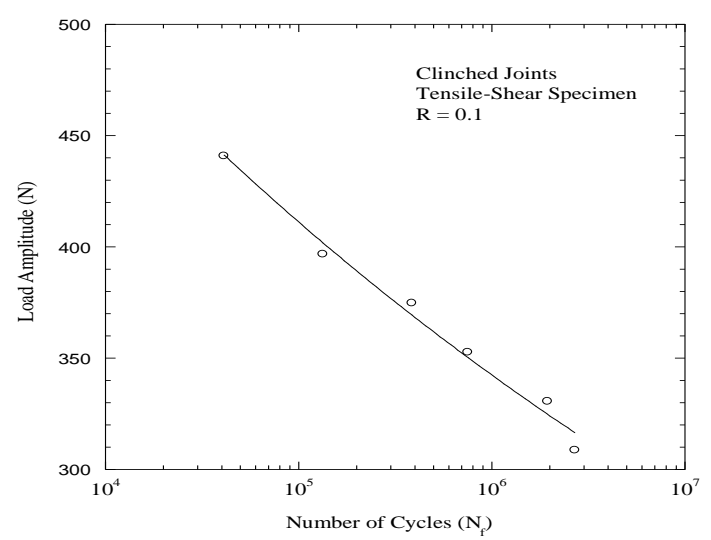

Fig. 5: Load Amplitude against the Number of Cycles for the Clinched Joint Specimens.

The results of the stress analysis at $\mathrm{P}=331 \mathrm{~N}$, which is the load amplitude corresponding to the fatigue strength at $2 \mathrm{x} 10^{6}$ cycles for the tensile-shear specimen, are shown in Fig. 6. As shown in Fig. 6, the maximum von-Mises stress occurs on the outer concave edge of the button corresponding to the neck of the upper sheet. This site coincides with the location where cracking was observed. It was confirmed that cracks initiated at this position and propagated through the thickness in the inside direction of the button, and the joint finally fractured. The von-Mises maximum stress level of $227 \mathrm{MPa}$ is slightly higher than the yield strength (=213.8 MPa) of the Al-5052 alloy. This suggests that the true strength of the neck is increased by cold clinch joining. This concept was confirmed by comparing the hardness of the neck area, where deformation was severe, and an area with only slight deformation. As shown in Fig. 7, the average hardness of the upper sheet regions with little deformation is approximately $74 \mathrm{Hv}$. However, the hardness of the neck of the upper sheet, where the maximum stress concentration occurs in Fig. 6, is approximately $83.5 \mathrm{Hv}$. Therefore, the strength of the neck region is increased due 
to work hardening. Consequently, it can be concluded that the maximum stress exceeds the yield strength. Moreover, it is considered that there is partially an effect of compressive residual stress in the neck region due to cold clinch joining.

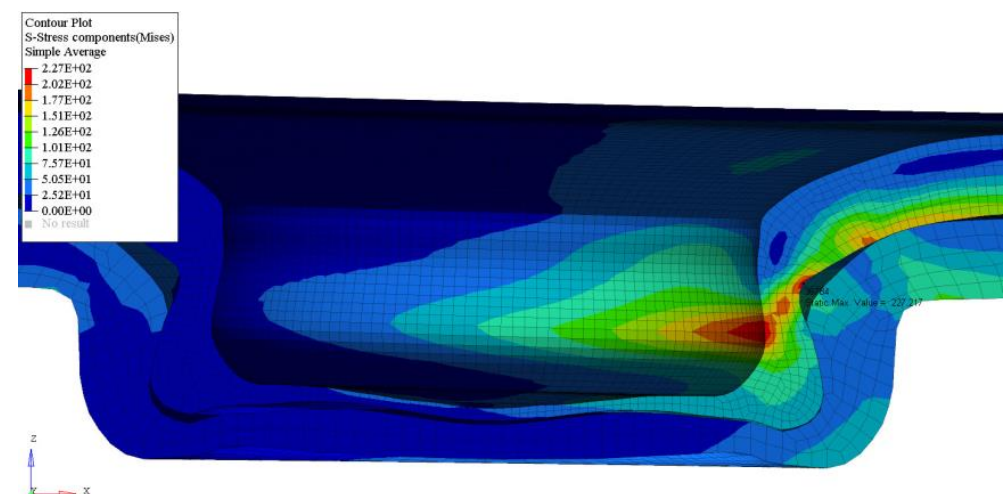

Fig. 6: Von-Mises Stress Distribution of the Joint When the Load Amplitude Is $331 \mathrm{~N}$.

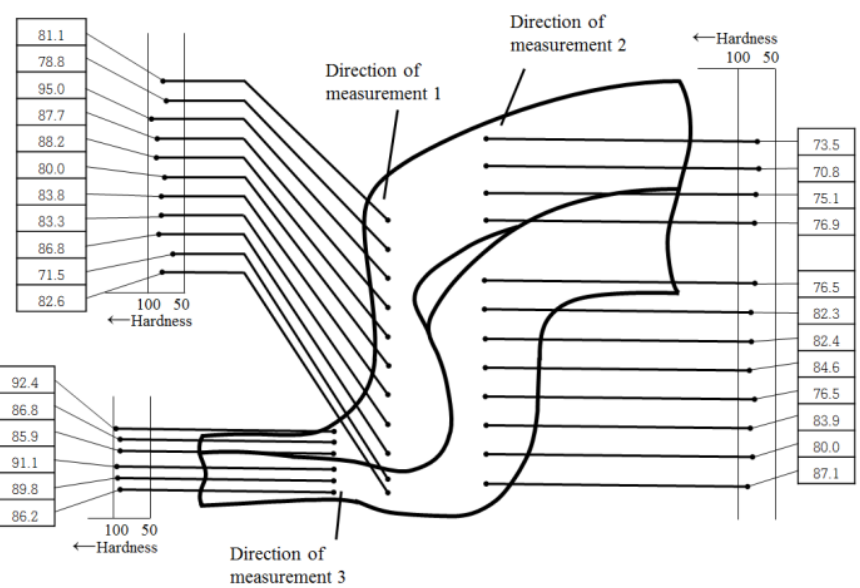

Fig. 7: Hardness Distribution of the Clinched Joint.

The von-Mises equivalent stress can be utilized to evaluate the fatigue strength of clinched joints, as the structural analysis results here reveal that the regions with the maximum von-Mises stress coincide with crack initiation sites in the specimen which failed due to fatigue. Therefore, the applied load amplitudes are converted into the form of von-Mises stress against the fatigue lifetimes in Fig. 8. The vonMises stress was determined to be $\sigma_{e q}=610.6 N_{f}^{-0.07}$.

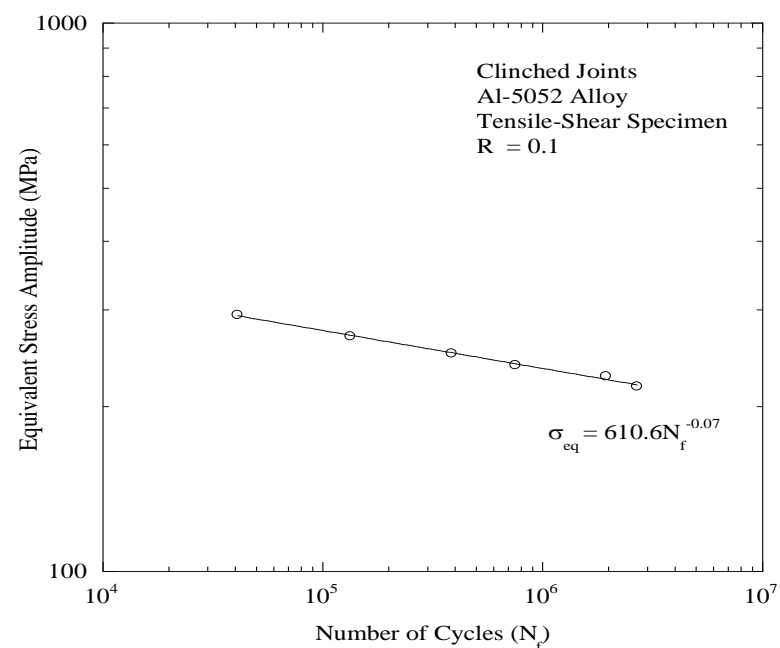

Fig. 8: Fatigue Lifetime as A Function of the Equivalent Stress Amplitude for the Tensile-Shear Specimens.

In general, the static strength of clinched joints is lower than that of spot welds or riveted joints. However, with regard to clinched joints, a direct comparison is impossible due to the dearth of test data on the fatigue strength of clinched joints and spot welds or rivet joints of identical materials. Therefore, it is necessary to conduct a comparison study of the fatigue strength capabilities of these joints with identical sheets, materials and joint diameters. Further study is also needed to determine the appropriate fatigue parameters to correlate the fatigue lifetimes of joints with different sheet material combinations, loading-type geometries, and other factors. 


\section{Conclusion}

In order to determine the optimum punching force required for the production of clinched joints made of upper and lower sheets of $0.8 \mathrm{~mm}$ - thick Al-5052 alloy, monotonic and fatigue tests were carried out using tensile-shear specimens. The results are summarized below.

1) The failure modes during a monotonic test of clinched joint are the interface failure mode and the pull-out failure mode. The interface failure mode refers to a case in which cracking occurs in the neck thickness. Meanwhile, the pull-out failure mode indicates a failure in the form of the upper and lower sheets of the button becoming separated with cracks initiating in the upper sheet of the button.

2) The fatigue test results with the clinched joints showed that the fatigue ratio is approximately $29 \%$, assuming a fatigue lifetime of 2 $\mathrm{x} 10^{6}$ cycles.

3) The maximum von-Mises stress of the joint at the load amplitude corresponding to the fatigue endurance limit is slightly higher than the yield strength of the Al-5052 alloy, suggesting that the strength of the neck region is increased partially due to work hardening.

\section{Acknowledgements}

This study was financially supported by Seoul National University of Science \& Technology.

\section{References}

[1] Gao S, Budde L, "Mechanism of mechanical press joining", Int. J. Mach. Tools Manf., Vol. 34, No.5, (1994), pp.641-657. https://doi.org/10.1016/0890-6955(94)90049-3.

[2] Sawhill JW, Sawdon SE, "A new mechanical joining technique for steel compared with spot welding”, SAE Tech. Paper Series, SAE830128, 1983. https://doi.org/10.4271/830128.

[3] Ning N, Ouyang K, Zhang Y, Qiao Z, Tao C, Li F, "Research on press joining technology for automotive metallic sheets", J. Mater. Proc. Technol., Vol.137, (2003), pp. 159-163. https://doi.org/10.1016/S0924-0136(02)01083-X.

[4] Kašćk L, Spišák E, Kubík R, Majerníková J, "The evaluation of properties of mechanically clinched joints made of ferrous and non-ferrous materials”, Adv. Sci. Tech. Res, J., Vol.12, No.1, (2018), pp. 162-170. https://doi.org/10.12913/22998624/85659.

[5] Kovács P, Tisza M, (2018) "Investigation of clinch joints made of similar and dissimilar materials", IOP Conf. Ser. Mater. Sci. Eng., 426, 012028, 2018. https://doi.org/10.1088/1757-899X/426/1/012028.

[6] Lin P, Su Z, Lai W, Pan J, "Fatigue behavior of self-piercing rivets and clinch joints in lap-shear specimens of aluminum sheets," SAE Int. J. Mater. Manf., Vol.6, No.2, (2013), pp. 293-298. https://doi.org/10.4271/2013-01-1024.

[7] Zhao SD, Xu F, Guo JH, Han XL, "Experimental and numerical research for the failure behavior of the clinched joint using modified Rousselier model", J. Mater. Proc. Technol., Vol.214, (2014), pp. 2134-2145. https://doi.org/10.1016/j.jmatprotec.2014.03.013.

[8] Carboni M, Beretta S, Monno M, "Fatigue behaviour of tensile-shear loaded clinched joints", Eng. Fracture Mech., Vol.73, (2006), pp. 178-190. https://doi.org/10.1016/i.engfracmech.2005.04.004.

[9] Kim JB, Kim HK, "Fatigue behavior of clinched joints in a steel sheet", Fatigue Fract. Eng. Mat. Struct., Vol.38, (2015), pp. 661-672. https://doi.org/10.1111/ffe.12263.

[10] Mucha J, Kašlák L, Spišák E, "The experimental analysis of forming and strength of clinch riveting sheet metal joint made of different materials", Adv. Mech. Eng., 848973, 2013. https://doi.org/10.1155/2013/848973.

[11] Tox corporation Tox ${ }^{\circledR}$ System user's guide.

[12] Lee YB, Park YK, Chung CS, Kim HK, An experimental study on the strength evaluation of mechanical press joint," J. Korean Society of Mech. Eng. A, Vol. 24, No.2, (2000), pp. 438-447.

[13] Kim HK, "Fatigue strength evaluation of the clinched lap joints of a cold rolled mild steel sheet," J. of Mat. Eng. Perform, Vol. 22, No.1, (2013), pp. 294-299. https://doi.org/10.1007/s11665-012-0232-1.

[14] Juvinall RC, (1967) "Engineering consideration of stress, strain and strength" McGraw-Hill, 1967.

[15] Saathoff DG, Mallick PK, "Static and fatigue strength evaluation of clinched joints in an aluminum alloy", SAE Tech. Paper 980693, 1998. https://doi.org/10.4271/980693. 